\title{
Small Molecule Modulators of RING-Type E3 Ligases: MDM and Cullin Families as Targets
}

\author{
Emil Bulatov ${ }^{1 *}$, Almaz Zagidullin ${ }^{2}$, Aygul Valiullina ${ }^{1}$, Regina Sayarova1 and \\ Albert Rizvanov ${ }^{1}$
}

1 Institute of Fundamental Medicine and Biology, Kazan Federal University, Kazan, Russia, ${ }^{2}$ A.E. Arbuzov Institute of Organic and Physical Chemistry, Kazan Scientific Center, Russian Academy of Sciences, Kazan, Russia

\section{OPEN ACCESS}

Edited by:

Yisong Wang,

National Institutes of Health (NIH),

United States

Reviewed by:

Harikumar K. B.

Rajiv Gandhi Centre

for Biotechnology, India

Paul B. Fisher

Virginia Commonwealth University,

United States

*Correspondence:

Emil Bulatov

chembio.kazan@gmail.com

Specialty section:

This article was submitted to

Cancer Molecular Targets

and Therapeutics,

a section of the journal

Frontiers in Pharmacology

Received: 23 December 2017

Accepted: 18 April 2018

Published: 08 May 2018

Citation:

Bulatov E, Zagidullin A, Valiullina A,

Sayarova R and Rizvanov A (2018)

Small Molecule Modulators of RING-Type E3 Ligases: MDM

and Cullin Families as Targets.

Front. Pharmacol. 9:450.

doi: 10.3389/fphar.2018.00450
Ubiquitin-proteasome system (UPS) is a primary signaling pathway for regulation of intracellular protein levels. E3 ubiquitin ligases, substrate-specific members of the UPS, represent highly attractive protein targets for drug discovery. The importance of E3 ligases as prospective targets for small molecule modulation is reinforced by ever growing evidence of their role in cancer and other diseases. To date the number of potent compounds targeting E3 ligases remains rather low and their rational design constitutes a challenging task. To successfully address this problem one must take into consideration the multi-subunit nature of many E3 ligases that implies multiple druggable pockets and protein-protein interfaces. In this review, we briefly cover the current state of drug discovery in the field of RING-type E3 ligases with focus on MDM and Cullin families as targets. We also provide an overview of small molecule chimeras that induce RING-type E3-mediated proteasomal degradation of substrate proteins of interest.

Keywords: ubiquitin-proteasome system, RING-type E3 ligases, MDM family, Cullin family, small molecules, induced protein degradation, PROTACs, SNIPERs

\section{INTRODUCTION}

In the last two decades, scientists around the globe paid increasing attention toward UPS, a primary pathway for regulation of protein turnover and removal of misfolded proteins in eukaryotic cells. The molecular mechanism of proteasomal protein degradation is driven by a consecutive action of three enzyme categories (E1 activating, E2 conjugating, and E3 ligating) that covalently tag substrate proteins with a chain of ubiquitins, small regulatory proteins (Hershko and Ciechanover, 1998; Pickart, 2001). Subsequent fate of the substrate is defined depending on type of ubiquitin linkage, its length and post-translational modifications. UPS operates in nucleus and cytoplasm, which enables ubiquitin-mediated regulation of cell cycle control, DNA damage response, innate immunity, and proteasomal protein degradation.

\footnotetext{
Abbreviations: ABL, Abelson tyrosine-protein kinase; AR, androgen receptor; $B C R$, breakpoint cluster region protein; BET, bromodomain and extra-terminal domain; BRD2, bromodomain-containing protein 2; cIAP1, cellular inhibitor of apoptosis protein 1; CRABP-II, cellular retinoic acid binding protein-II; CRL, cullin RING E3 ligase; ER $\alpha$, estrogen receptor $\alpha$; FANC, Fanconi anemia ligase; HIF1 $\alpha$, hypoxia-induced factor 1- $\alpha$; IAP, inhibitor of apoptosis protein; MDM2, murine double minute 2; NAE, NEDD8-activating enzyme; NEDD8, neural precursor cell expressed developmentally down-regulated protein 8; NOTCH1, neurogenic locus notch homolog protein 1; PDE4, cAMP-specific $3^{\prime}, 5^{\prime}$-cyclic phosphodiesterase 4; POI, protein of interest; PROTAC, proteolysis-targeting chimera; RBR, RING-between RING-RING; RING, really interesting new gene; SARM, selective androgen receptor modulator; SNIPER, specific and non-genetic IAP-dependent protein erasers; UPS, ubiquitin-proteasome system; VHL, von Hippel-Lindau; XIAP, X-linked inhibitor of apoptosis protein.
} 
E3 ligases confer substrate specificity of the whole UPS and function via two primary mechanisms - they can play an intermediary catalytic role in transfer of ubiquitins from $\mathrm{E} 2 \sim \mathrm{Ub}$ conjugate to the substrate or, alternatively, facilitate direct ubiquitin transfer bypassing the E3 ligase itself. The first mechanism is common for Homologous to E6-AP Carboxy Terminus (HECT)-type E3s, whereas the second one is typical for RING-type E3s.

Initially the RING domain was identified in RING1 protein and later confirmed to be a structural element of Rbx1 that functions as E2-recruiting subunit of E3 ligase (Kamura et al., 1999; Ohta et al., 1999; Seol et al., 1999; Tan et al., 1999). The canonical RING finger motif can be represented as Cys- $\mathrm{X}_{2}-\mathrm{Cys}-\mathrm{X}_{(9-39)}$-Cys- $\mathrm{X}_{(1-3)}$-His- $\mathrm{X}_{(2-3)}$-Cys$\mathrm{X}_{2}$-Cys- $\mathrm{X}_{(4-48)}-$ Cys- $\mathrm{X}_{2}$-Cys, where $\mathrm{X}$ is any other amino acid (Deshaies and Joazeiro, 2009). The domain includes two $\mathrm{Zn}^{2+}$ coordinated loops and intervening central $\alpha$-helix that together form a conserved structural platform for anchoring the E2 conjugating enzyme.

RING E3s can be categorized according to the form of subunit organization: (1) mono-subunit ligases like MDM and Cbl; (2) multi-subunit complexes such as CRL, anaphase promoting complex/cyclosome (APC/C) (Castro et al., 2005) and FANC (Metzger et al., 2014). Another important RING family members are RBRs, the single subunit enzymes with multiple RING domains (Spratt et al., 2014). In addition, worth mentioning are U-box ligases, containing atypical RING domains without coordinated $\mathrm{Zn}^{2+}$ ions, that are often featured as separate from canonical RING E3s (Hatakeyama et al., 2001).

Notably, E3 ligases were proposed to become the "new kinases" owing to the significant therapeutic and market potential of their small molecule inhibitors (Cohen and Tcherpakov, 2010). Recent advances demonstrated that E3s in general, and MDM and Cullin families (Figures 1A,B), in particular, have captured significant attention of the research community due to their key role in poly-ubiquitination of substrate proteins (Maniaci et al., 2017).

Here, we briefly highlight members of MDM and CRL families of RING-type E3 ligases, their primary functions and small molecule modulation.

\section{MDM FAMILY - MDM2 AND MDM4}

MDM family includes MDM2 and its homolog MDM4 (also known as MDMX). Both enzymes are overexpressed in many cancers and function as key negative regulators of oncosuppressor protein p53 that is often referred to as "guardian of the genome" (Haupt et al., 2017). MDM2-MDM4p53 signaling circuit regulates core metabolic pathways that involve DNA damage response, induction of apoptosis, cell cycle arrest, and senescence. In nearly half of cancers p53 is downregulated due to overexpression of MDM2 or/and MDM4, while the other half is caused by tumorigenic missense mutations of p53, mostly occurring in DNA-binding domain (Muller and Vousden, 2013).
MDM2 binds wild-type p53 with high affinity, blocks its transcriptional activator functions and regulates its nuclear export, stability, intracellular levels (Geyer et al., 2000). MDM4 shares a high structural homology with MDM2, mainly in the $\mathrm{N}$-terminal p53-binding domain, yet due to low E3 ligase activity its overexpression does not lead to dramatic p53 downregulation (Huang et al., 2011). Interaction of MDM2 and MDM4 via their RING domains results in formation of MDM2/MDM4 hetero-dimeric complex that enhances p53 ubiquitination and degradation (Pant et al., 2011).

Many therapeutic strategies based on disrupting p53/MDM2 protein-protein interaction are aimed to stabilize and activate p53 in order to initiate programmed cell death in cancers with overexpressed MDM2 (Zhang et al., 2015). Numerous examples of MDM2 inhibitors include small synthetic molecules such as Nutlin-3a (Vassilev et al., 2004), RG7112 (Vu et al., 2013), NU8231 (Hardcastle et al., 2011), MI773 (Zhao et al., 2013), CGM097 (Holzer et al., 2015) with several others already in clinical trials as drug candidates (Tisato et al., 2017) (Figure 1A). Development of potent MDM2 inhibitors remains a longstanding mainstream in the p53 field, meanwhile the importance of therapeutic targeting MDM4 was recognized later. To date a certain progress was achieved in development of p53/MDM4 inhibitors such as SJ-172550 (Reed et al., 2010; Bista et al., 2012), WK298 (Popowicz et al., 2010) and stabilized peptide SAH-p53-c8 (Bernal et al., 2010).

In addition, simultaneous inhibition of both MDM2 and MDM4 enzymes, i.e., by means of dual inhibitors, was proposed to enhance p53 activation (Hu et al., 2007; Popowicz et al., 2010; Zaytsev et al., 2015). Stapled peptide ALRN-6924 (Aileron, Inc.) is an example of dual inhibitor that is currently undergoing clinical trials against solid tumors and lymphomas (Chang et al., 2013). Also, worth mentioning an approach based on targeting MDM2/MDM4 interface with short peptides that initiate p53induced apoptosis and slowdown of tumor growth (Pellegrino et al., 2015).

\section{CULLIN FAMILY - CULLIN RING E3 LIGASES (CRLs)}

Cullin RING E3 ligases constitute the largest family of E3 ligases with over 200 known members (Sarikas et al., 2011). In certain cell types up to $20 \%$ of the proteasomal protein degradation is mediated by CRLs (Soucy et al., 2009). Classification of CRL family is based on type of Cullin scaffold serving as a backbone of the multi-subunit protein complex. The evolutionary conserved Cullin protein has several forms that share structural similarity - Cul1, Cul2, Cul3, Cul4A, Cul4B, Cul5, and Cul7. Accordingly, the resulting E3 ligases are named CRL1-CRL7. Some classifications also include Cul9 known as p53-associated parkin-like cytoplasmic protein (PARC) (Li and Xiong, 2017).

Assembly of the multi-subunit CRLs was originally reported for the archetypal Skp1-Cul1-Rbx1 complex (Feldman et al., 1997). The CRL structure is based on modular organization of 
A

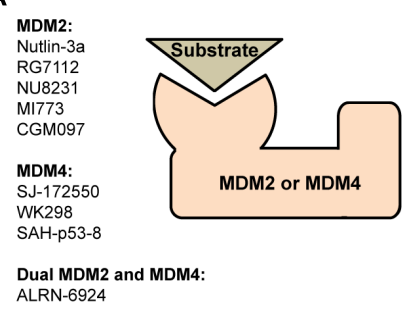

B

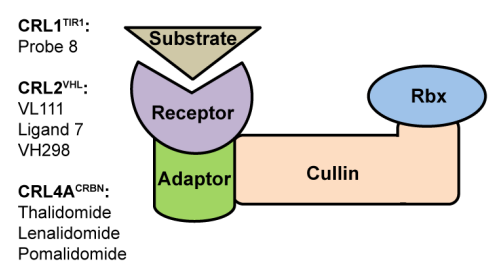

c

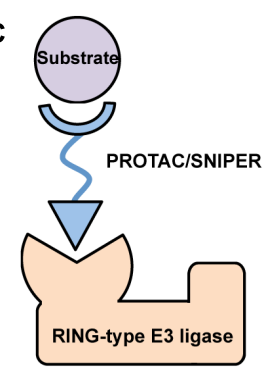

FIGURE 1 | Structural organization of (A) MDM and (B) CRL RING-type E3 ubiquitin ligases and a brief list of their most potent modulators. MDM2 and MDM4 are single subunit proteins containing C-terminal RING finger domain. In contrast, CRLs are constituted of several subunits, such as receptor, adaptor, Cullin scaffold and RING-box protein. (C) Schematic representation of PROTAC/SNIPER molecule acting to induce ubiquitination and subsequent proteasomal degradation of substrate protein of interest. These small molecule degraders contain substrate-specific component, short linker, and E3-specific component.

constituent subunits such as substrate receptors (F-box, SOCSbox, DCAF, and BTB), adaptors (Skp1, ElonginB, ElonginC, DDB1, and BTB), Cullin scaffolds (Cul1-Cul7 and Cul9) and RING finger proteins ( $\mathrm{Rbx} 1$ and $\mathrm{Rbx} 2)$. The wide range of building blocks and their combinations enables formation of a multitude of functionally diverse E3 ligases (Bosu and Kipreos, 2008; Sarikas et al., 2011; Lydeard et al., 2013). Full-size CRLs are notoriously difficult to obtain and characterize, to date only several complexes containing a complete set of subunits were reported, including SOCS2-EloB-EloC-Cul5-Rbx2 (Bulatov et al., 2015), VHL-EloB-EloC-Cul5-Rbx1 (Cardote et al., 2017), Skp2Skp1-Cul1-Rbx1 (Zheng et al., 2002), DDB2-DDB1-Cul4A-Rbx1 (Fischer et al., 2011).

Drug discovery in the CRL field keeps advancing, driven by foreseeable role of these enzymes as targets in numerous human diseases (Petroski, 2008; Cohen and Tcherpakov, 2010; AndéricaRomero et al., 2013; Zhao and Sun, 2013). The CRLs as drug targets are promising, yet highly sophisticated due to diverse putative combinations of structural components that result in multiple protein-protein interfaces.

The growing number of reported CRL crystal structures includes full-size enzymes, individual components and their complexes. Here, particularly important are structures of receptor subunits with bound small molecules because they provide crucial information for rational design of potent modulators. Examples (Figure 1B) include Probe 8, auxin-mimic that disrupts interaction between TIR1 (receptor in CRL1 ${ }^{\text {TIR1}}$ ) and its substrate Aux/IAA (Hayashi et al., 2008); VL111, Ligand 7 and their enhanced analog VH298 that inhibit binding of VHL protein (receptor in CRL2 ${ }^{\mathrm{VHL}}$ ) to substrate hypoxia-inducible factor 1-alpha (HIF1 $\alpha$ ) (Buckley et al., 2012; Galdeano et al., 2014; Soares et al., 2018); thalidomide and its derivatives lenalidomide, pomalidomide that modulate CRL4A ${ }^{\mathrm{CRBN}}$ activity by binding to its CRBN receptor subunit (Chamberlain et al., 2014; Fischer et al., 2014).

Targeting CRLs for therapeutic applications is obstructed by several factors. Firstly, there is no general approach and each enzyme has to be tackled individually according to its structural and functional characteristics. Secondly, CRLs are complex molecular entities assembled from several independent subunits that form a number of protein-protein interfaces and druggable pockets. Surprisingly, the apparent complexity of this multi-subunit system might turn out to be an advantage the multitude of interfaces and pockets provides additional opportunities for design of specific binders (Bulatov and Ciulli, 2015). Small molecules modulate CRL activity directly by inhibiting substrate/receptor interaction, disrupting CRL assembly, inducing allosteric conformational shifts that lead to suppressed activity or altered ensemble dynamics (Lee and Craik, 2009). In some cases modulators stabilize specific proteinprotein interactions within the CRL complex (Thiel et al., 2012).

\section{RING-TYPE E3 LIGASES AS TARGETS FOR DRUG DISCOVERY}

Drug discovery in the UPS field thrived since FDA approval of $26 \mathrm{~S}$ proteasome inhibitors Bortezomib (approved in 2003, marketed as Velcade ${ }^{\circledR}$ ) and more recently Carfilzomib (approved in 2012, marketed as Kyprolis ${ }^{\circledR}$ ) for treatment of multiple myeloma. Although proteasome inhibitors demonstrate selectivity toward tumor cells and lead to apoptosis, they also suppress proteasome-mediated degradation of all intracellular proteins resulting in potential side effects (Shibata et al., 2018). In addition to that, many patients were demonstrated to develop resistance toward Bortezomib that acts as a reversible competitive inhibitor of $26 \mathrm{~S}$ proteasome (Ohoka et al., 2018). Strategies to overcome the resistance include design of inhibitors with alternative mechanism of action, i.e., Carfilzomib covalently binds proteasome and causes its irreversible inhibition.

Another emerging and highly promising strategy is to target different levels of ubiquitination cascade upstream of proteasome, mainly E1, E2, and E3 enzymes (Shibata et al., 2017). Here, E3 ligases determine substrate specificity and, therefore, represent primary molecular targets for small molecule modulation. Development of potent E3 ligase modulators is risky and challenging task complicated by diverse protein-protein interfaces of the multi-component complexes, lack of a classical enzymatic/catalytic active site and specificity problems stipulated by a variety of potential substrates.

RING-type E3 ligases were previously successfully targeted using small molecule inhibitors of protein-protein interactions, 
i.e., binding at substrate/receptor HIF1 $\alpha /$ VHL (Ohoka et al., 2017b), p53/MDM2 and p53/MDM4 interfaces (Ohoka et al., 2017a), adaptor/receptor interface Skp1/Skp2 (Chen et al., 2008) and several other, as reviewed in Bulatov and Ciulli (2015).

In addition, it would be reasonable to mention an auxiliary protein NEDD8 that serves as crucial regulator of CRL functions (Soucy et al., 2009). The ubiquitin-like protein NEDD8 gets covalently conjugated to a specific conserved lysine residue at C-terminal domain of Cullin scaffold in a process termed NEDDylation. NEDD8 conjugation enhances substrate ubiquitination by promoting CRL dynamics and inducing conformational shift of the protein ensemble that brings together E3-bound substrate and $\mathrm{Rbx}-\mathrm{E} 2 \sim \mathrm{Ub}$ (Duda et al., 2008, 2011). In addition, MDM2 was demonstrated not only to autoNEDDylate itself, but also to mediate p53 NEDDylation that inhibits its transcriptional activity (Xirodimas et al., 2004). Pevonedistat (also known as MLN4924), a firstin-class selective inhibitor of NEDD8-activating enzyme (NAE) that mediates NEDDylation, is currently undergoing several clinical trials against different types of cancer (Swords et al., 2015).

\section{TARGETED PROTEIN DEGRADATION MEDIATED BY RING-TYPE E3 LIGASES}

A novel paradigm-shifting approach that dramatically increases the attractiveness of $\mathrm{E} 3$ ligases as targets for drug design is based on proteolysis-targeting chimeras (PROTACs) (Buckley and Crews, 2014; Lai and Crews, 2017). These are heterobifunctional compounds with bivalent selectivity, they consist of three key elements: substrate-specific component ("warhead"), short linker, and E3-specific component. PROTACs bind and bring into close proximity substrate protein of interest (POI) and E3 ligase thus facilitating E3-mediated ubiquitination of the substrate (Figure 1C). This approach, sometimes called as "chemical knockdown," enables ligand-induced degradation of specific endogenous proteins (Bondeson et al., 2015).

Historically the first small-molecule-based PROTAC degrader was developed for recruiting MDM2 E3 ligase by Nutlin3a imidazoline derivative, as reported by Crews laboratory (Schneekloth et al., 2008). In this study androgen receptor (AR) was targeted by SARM compound connected to Nutlin-3a moiety via PEG-based linker. Treatment of AR-expressing HeLa cells with SARM-Nutlin-3a bivalent molecule resulted in depletion of AR levels. Since then there were no subsequent reports of MDM2-mediated PROTACs, though given the large and still expanding repertoire of potent MDM2 inhibitors it would be reasonable to expect much higher interest in such degraders.

$\mathrm{CRL}^{\mathrm{VHL}}$ is the most prominent example of E3 ligase directed by PROTACs to ubiquitinate a recruited substrate protein and result in its proteasomal degradation. The E3specific component is designed to mimic HIFl $\alpha$, natural substrate of VHL receptor, post-translationally hydroxylated at prolines 402 and/or 564. Examples of proteins selectively targeted by PROTACs via CRL2 ${ }^{\mathrm{VHL}}$-mediated mechanism include BET family of epigenetic regulators $\mathrm{BRD} 2, \mathrm{BRD} 3$, and
BRD4 (Zengerle et al., 2015; Raina et al., 2016; Gadd et al., 2017; Zhou et al., 2017; Chan et al., 2018), steroid hormone receptor ERR $\alpha$ and serine-threonine kinase RIPK2 (Bondeson et al., 2015). Another recent study demonstrated successful degradation of oncogenic tyrosine kinase BCR-ABL using both $\mathrm{CRL}_{2} \mathrm{VHL}_{-}$and CRL4A ${ }^{\mathrm{CRBN}}$-specific PROTACs (Lai et al., 2016). Here, FDA-approved tyrosine kinase inhibitors Bosutinib and Dasatinib served as PROTAC "warheads," whereas hydroxy-proline derivative and pomalidomide were used as $\mathrm{CRL}_{2}{ }^{\mathrm{VHL}}$ - and $\mathrm{CRL} 4 \mathrm{~A}^{\mathrm{CRBN}}$-binding components, respectively. Similarly, PROTAC-directed CRL4A ${ }^{\text {CRBN }}$-mediated target degradation also includes BRD4 and cytosolic protein FKBP12 (Lu et al., 2015; Winter et al., 2015). In addition, Ciulli laboratory recently reported curious example of the first homo-bivalent PROTAC (Homo-PROTAC) that simultaneously recruits two CRL2 ${ }^{\mathrm{VHL}}$ molecules and induces their suicidal self-degradation (Maniaci et al., 2017). Highly potent Homo-PROTAC CM11 contains two molecules of the previously described VH298 compound connected via polyethylene glycol linker (Frost et al., 2016; Soares et al., 2018).

SNIPERs, an abbreviated form of specific and non-genetic IAP-dependent protein erasers, are a class of small-molecule degraders similar to PROTACs (Itoh et al., 2010, 2011). These compounds recruit IAP family of RING-type E3 ligases - cIAP1, cIAP2, and XIAP. The SNIPER chemical structure consists of selective IAP antagonist (i.e., Bestatin, MV1, and LCL161), PEG linker and peptide- or small-molecule-based POI-specific component. The initial concept was further explored by Naito laboratory that recently demonstrated selective proteasomal

TABLE 1 | List of substrate proteins targeted by PROTACs and SNIPERs for RING-type E3-mediated proteasomal degradation.

\begin{tabular}{|c|c|c|}
\hline Substrate & RING-type E3 ligase & Reference \\
\hline \multicolumn{3}{|l|}{ PROTACs } \\
\hline AR & MDM2 & $\begin{array}{l}\text { Schneekloth et al., } \\
2008\end{array}$ \\
\hline BRD2, BRD3, BRD4 & $\mathrm{CRL2}{ }^{\mathrm{VHL}}$ & $\begin{array}{l}\text { Thiel et al., 2012; } \\
\text { Zengerle et al., 2015; } \\
\text { Raina et al., 2016; } \\
\text { Gadd et al., 2017; } \\
\text { Chan et al., } 2018\end{array}$ \\
\hline ERR $\alpha$, RIPK2 & CRL2 $2^{V H L}$ & Bondeson et al., 2015 \\
\hline VHL & $\mathrm{CRL} 2^{\mathrm{VHL}}$ & Maniaci et al., 2017 \\
\hline BCR-ABL & CRL2 ${ }^{\mathrm{VHL}}, \mathrm{CRL} 4 \mathrm{~A}^{\mathrm{CRBN}}$ & Lai et al., 2016 \\
\hline FKBP12 & $\mathrm{CRL} 4 \mathrm{~A}^{\mathrm{CRBN}}$ & Winter et al., 2015 \\
\hline BRD4 & CRL4A $\mathrm{CRBN}$ & $\begin{array}{l}\text { Lu et al., 2015; Winter } \\
\text { et al., } 2015\end{array}$ \\
\hline
\end{tabular}

\section{SNIPERs}

AR

$E R \alpha$

CIAP1/CIAP2/XIAP

Shibata et al., 2018

BCR-ABL

Ohoka et al., 2018

BRD4

PDE4

Shibata et al., 2017

Ohoka et al., 2017b

Ohoka et al., 2017b

$\mathrm{NOTCH} 1$

Ohoka et al., 2017a

CRABP-II 
degradation of a range of substrate proteins, including $\mathrm{ER} \alpha$ (Ohoka et al., 2018), BCR-ABL (Shibata et al., 2017), BRD4 and PDE4 (Ohoka et al., 2017b), NOTCH1 (Ohoka et al., 2017a), CRABP-II (Okuhira et al., 2011).

These examples, listed in Table 1, illustrate that induced protein depletion mediated by small molecule degraders (PROTACs and SNIPERs) specific for certain RING-type E3 ligases (MDMs, CRLs, and IAPs) is a justified paradigm for drug discovery. These compounds operate in sub-stoichiometric manner and catalyze enzymatic removal of substrate POIs (chemical knockdown) rather than their inhibition via binding site occupation. The PROTAC/SNIPER-based approach counteracts restoration of intracellular POI levels and is seen as a promising addition to conventional gene knockdown techniques (i.e., RNAi, antisense oligonucleotides, and CRISPR/Cas9) (Crews, 2018).

\section{CONCLUSION}

Many E3 ubiquitin ligases are implicated in cellular physiology and homeostasis at multiple regulatory levels, play crucial roles in a wide range of human diseases, including cancer and inflammatory disorders. The RING-type ligases represent the largest class of E3s in humans and are responsible for recognition, poly-ubiquitination and subsequent proteasomal degradation of numerous substrate proteins. Given the structural intricacy of RING-type E3s and their diverse functions it is essential to understand molecular principles that govern assembly and interactions of subunits within the protein complex. We anticipate a forthcoming re-focusing of research efforts from structural/functional characterization of these enzymes to rational design of precision molecular tools capable of modulating E3 activity in living cells and organisms. One could envisage that targeted therapeutic action upstream of proteasome could potentially lead to emerging resistance caused by feedbackdriven compensatory mechanisms. This could potentially be overcome by administering a synergistic combination of drugs that act via distinct molecular mechanisms.

The MDM and CRL families of RING-type E3s are growing in importance as attractive targets for small molecule therapeutics that could operate not only as inhibitors but also activators of enzymatic activity, disruptors and stabilizers of protein-protein

\section{REFERENCES}

Andérica-Romero, A. C., González-Herrera, I. G., Santamaría, A., and PedrazaChaverri, J. (2013). Cullin 3 as a novel target in diverse pathologies. Redox Biol. 1, 366-372. doi: 10.1016/j.redox.2013.07.003

Bernal, F., Wade, M., Godes, M., Davis, T. N., Whitehead, D. G., Kung, A. L., et al. (2010). A stapled p53 helix overcomes HDMX-mediated suppression of p53. Cancer Cell 18, 411-422. doi: 10.1016/j.ccr.2010.10.024

Bista, M., Smithson, D., Pecak, A., Salinas, G., Pustelny, K., Min, J., et al. (2012). On the mechanism of action of SJ-172550 in inhibiting the interaction of MDM4 and p53. PLoS One 7:e37518. doi: 10.1371/journal.pone.003 7518

Bondeson, D. P., Mares, A., Smith, I. E. D., Ko, E., Campos, S., Miah, A. H., et al. (2015). Catalytic in vivo protein knockdown by small-molecule PROTACs. Nat. Chem. Biol. 11, 611-617. doi: 10.1038/nchembio.1858 interactions, regulators of protein dynamics. The availability of $\mathrm{X}$-ray structural data, especially for full-size enzymes, remains to be one the main limitations for structure-based design of modulators for multi-subunit E3 complexes. Nevertheless, slow yet steady increase of solved crystal structures of RING-type E3s and their ligand-bound complexes provides opportunities for further rational design of highly potent modulators. General strategies for discovery of novel E3 modulators include in vitro screening of compound libraries using functional assays (i.e., ubiquitination assay) (Sun, 2005); software packages (i.e., ICM-Pocket Finder) predicting druggable pockets for subsequent in silico ligand screening and docking (Cardozo and Abagyan, 2005); fragment-based discovery and rational structure elaboration (Van Molle et al., 2012; Gadd et al., 2015).

In addition, PROTAC/SNIPER-induced ubiquitination and intracellular degradation of specific substrates offers an added layer of specificity and constitutes an emerging strategy for post-translational regulation of protein levels. These compounds demonstrate high potential for a novel modality of chemical intervention on UPS and hold much promise as prospective therapeutic candidates. Such chemical protein knockdown technologies based on RING-type E3 modulation still remain largely untapped by the pharmaceutical industry, however, it is reasonable to expect a major progress in this direction in near future.

\section{AUTHOR CONTRIBUTIONS}

EB wrote introduction, conclusion, sections about Cullin family and targeted protein degradation. AV and RS wrote section about MDM family. AZ and AR wrote section about drug discovery.

\section{FUNDING}

This study was supported by grant 16-34-60213 mol_a_dk from the Russian Foundation for Basic Research (RFBR). AV and RS were supported by grant of the President of Russian Federation MK-4253.2018.4. The work was performed according to the Russian Government Program of Competitive Growth of Kazan Federal University.

Bosu, D. R., and Kipreos, E. T. (2008). Cullin-RING ubiquitin ligases: global regulation and activation cycles. Cell Div. 3:7. doi: 10.1186/1747-10 28-3-7

Buckley, D. L., and Crews, C. M. (2014). Small-molecule control of intracellular protein levels through modulation of the ubiquitin proteasome system. Angew. Chem. Int. Ed. Engl. 53, 2312-2330. doi: 10.1002/anie.201307761

Buckley, D. L., Van Molle, I., Gareiss, P. C., Tae, H. S., Michel, J., Noblin, D. J., et al. (2012). Targeting the von Hippel-Lindau E3 ubiquitin ligase using small molecules to disrupt the VHL/HIF-1 $\alpha$ interaction. J. Am. Chem. Soc. 134, 4465-4468. doi: 10.1021/ja209924v

Bulatov, E., and Ciulli, A. (2015). Targeting Cullin-RING E3 ubiquitin ligases for drug discovery: structure, assembly and small-molecule modulation. Biochem. J. 467, 365-386. doi: 10.1042/BJ20141450

Bulatov, E., Martin, E. M., Chatterjee, S., Knebel, A., Shimamura, S., Konijnenberg, A., et al. (2015). Biophysical studies on interactions and assembly 
of full-size E3 ubiquitin ligase: suppressor of cytokine signaling 2 (SOCS2)elongin BC-cullin 5-ring box protein 2 (RBX2). J. Biol. Chem. 290, 4178-4191. doi: $10.1074 /$ jbc.M114.616664

Cardote, T. A. F., Gadd, M. S., and Ciulli, A. (2017). Crystal structure of the Cul2-Rbx1-EloBC-VHL ubiquitin ligase complex. Structure 25, 901.e3-911.e3. doi: 10.1016/j.str.2017.04.009

Cardozo, T., and Abagyan, R. (2005). Druggability of SCF ubiquitin ligase-protein interfaces. Methods Enzymol. 399, 634-653. doi: 10.1016/S0076-6879(05) 99042-3

Castro, A., Bernis, C., Vigneron, S., Labbé, J.-C., and Lorca, T. (2005). The anaphase-promoting complex: a key factor in the regulation of cell cycle. Oncogene 24, 314-325. doi: 10.1038/sj.onc.1207973

Chamberlain, P. P., Lopez-Girona, A., Miller, K., Carmel, G., Pagarigan, B., ChieLeon, B., et al. (2014). Structure of the human Cereblon-DDB1-lenalidomide complex reveals basis for responsiveness to thalidomide analogs. Nat. Struct. Mol. Biol. 21, 803-809. doi: 10.1038/nsmb.2874

Chan, K.-H., Zengerle, M., Testa, A., and Ciulli, A. (2018). Impact of target warhead and linkage vector on inducing protein degradation: comparison of bromodomain and extra-terminal (BET) degraders derived from triazolodiazepine (JQ1) and tetrahydroquinoline (I-BET726) BET Inhibitor scaffolds. J. Med. Chem. 61, 504-513. doi: 10.1021/acs.jmedchem.6b0 1912

Chang, Y. S., Graves, B., Guerlavais, V., Tovar, C., Packman, K., To, K.H., et al. (2013). Stapled $\alpha$-helical peptide drug development: a potent dual inhibitor of MDM2 and MDMX for p53-dependent cancer therapy. Proc. Natl. Acad. Sci. U.S.A. 110, E3445-E3454. doi: 10.1073/pnas.130300 2110

Chen, Q., Xie, W., Kuhn, D. J., Voorhees, P. M., Lopez-Girona, A., Mendy, D., et al. (2008). Targeting the p27 E3 ligase SCF(Skp2) results in p27- and Skp2mediated cell-cycle arrest and activation of autophagy. Blood 111, 4690-4699. doi: 10.1182/blood-2007-09-112904

Cohen, P., and Tcherpakov, M. (2010). Will the ubiquitin system furnish as many drug targets as protein kinases? Cell 143, 686-693. doi: 10.1016/j.cell. 2010.11.016

Crews, C. M. (2018). Inducing protein degradation as a therapeutic strategy. J. Med. Chem. 61, 403-404. doi: 10.1021/acs.jmedchem.7b01333

Deshaies, R. J., and Joazeiro, C. A. P. (2009). RING domain E3 ubiquitin ligases. Апnu. Rev. Biochem. 78, 399-434. doi: 10.1146/annurev.biochem.78.101807. 093809

Duda, D. M., Borg, L. A., Scott, D. C., Hunt, H. W., Hammel, M., and Schulman, B. A. (2008). Structural insights into NEDD8 activation of cullin-RING ligases: conformational control of conjugation. Cell 134, 995-1006. doi: 10.1016/j.cell. 2008.07.022

Duda, D. M., Scott, D. C., Calabrese, M. F., Zimmerman, E. S., Zheng, N., and Schulman, B. A. (2011). Structural regulation of cullin-RING ubiquitin ligase complexes. Curr. Opin. Struct. Biol. 21, 257-264. doi: 10.1016/j.sbi.2011. 01.003

Feldman, R. M., Correll, C. C., Kaplan, K. B., and Deshaies, R. J. (1997). A complex of Cdc4p, Skp1p, and Cdc53p/cullin catalyzes ubiquitination of the phosphorylated CDK inhibitor Siclp. Cell 91, 221-230. doi: 10.1016/S00928674(00)80404-3

Fischer, E. S., Böhm, K., Lydeard, J. R., Yang, H., Stadler, M. B., Cavadini, S., et al. (2014). Structure of the DDB1-CRBN E3 ubiquitin ligase in complex with thalidomide. Nature 512, 49-53. doi: 10.1038/nature 13527

Fischer, E. S., Scrima, A., Böhm, K., Matsumoto, S., Lingaraju, G. M., Faty, M., et al. (2011). The molecular basis of CRL4DDB2/CSA ubiquitin ligase architecture, targeting, and activation. Cell 147, 1024-1039. doi: 10.1016/j.cell.2011. 10.035

Frost, J., Galdeano, C., Soares, P., Gadd, M. S., Grzes, K. M., Ellis, L., et al. (2016). Potent and selective chemical probe of hypoxic signalling downstream of HIF$\alpha$ hydroxylation via VHL inhibition. Nat. Commun. 7:13312. doi: 10.1038/ ncomms 13312

Gadd, M. S., Bulatov, E., and Ciulli, A. (2015). Serendipitous SAD Solution for DMSO-Soaked SOCS2-ElonginC-ElonginB crystals using covalently incorporated dimethylarsenic: insights into substrate receptor conformational flexibility in cullin RING ligases. PLoS One 10:e0131218. doi: 10.1371/journal. pone. 0131218
Gadd, M. S., Testa, A., Lucas, X., Chan, K.-H., Chen, W., Lamont, D. J., et al. (2017). Structural basis of PROTAC cooperative recognition for selective protein degradation. Nat. Chem. Biol. 13, 514-521. doi: 10.1038/nchembio. 2329

Galdeano, C., Gadd, M. S., Soares, P., Scaffidi, S., Van Molle, I., Birced, I., et al. (2014). Structure-guided design and optimization of small molecules targeting the protein-protein interaction between the von Hippel-Lindau (VHL) E3 ubiquitin ligase and the hypoxia inducible factor (HIF) alpha subunit with in vitro nanomolar affinities. J. Med. Chem. 57, 8657-8663. doi: 10.1021/ jm5011258

Geyer, R. K., Yu, Z. K., and Maki, C. G. (2000). The MDM2 RING-finger domain is required to promote p53 nuclear export. Nat. Cell Biol. 2, 569-573. doi: $10.1038 / 35023507$

Hardcastle, I. R., Liu, J., Valeur, E., Watson, A., Ahmed, S. U., Blackburn, T. J., et al. (2011). Isoindolinone inhibitors of the murine double minute 2 (MDM2)p53 protein-protein interaction: structure-activity studies leading to improved potency. J. Med. Chem. 54, 1233-1243. doi: 10.1021/jm1011929

Hatakeyama, S., Yada, M., Matsumoto, M., Ishida, N., and Nakayama, K. I. (2001). $\mathrm{U}$ box proteins as a new family of ubiquitin-protein ligases. J. Biol. Chem. 276, 33111-33120. doi: 10.1074/jbc.M102755200

Haupt, S., Vijayakumaran, R., Miranda, P. J., Burgess, A., Lim, E., and Haupt, Y. (2017). The role of MDM2 and MDM4 in breast cancer development and prevention. J. Mol. Cell Biol. 9, 53-61. doi: 10.1093/jmcb/mjx007

Hayashi, K.-I., Tan, X., Zheng, N., Hatate, T., Kimura, Y., Kepinski, S., et al. (2008). Small-molecule agonists and antagonists of F-box protein-substrate interactions in auxin perception and signaling. Proc. Natl. Acad. Sci. U.S.A. 105, 5632-5637. doi: 10.1073/pnas.0711146105

Hershko, A., and Ciechanover, A. (1998). The ubiquitin system. Annu. Rev. Biochem. 67, 425-479. doi: 10.1146/annurev.biochem.67.1.425

Holzer, P., Masuya, K., Furet, P., Kallen, J., Valat-Stachyra, T., Ferretti, S., et al. (2015). Discovery of a dihydroisoquinolinone derivative (NVP-CGM097): a highly potent and selective MDM2 inhibitor undergoing phase 1 clinical trials in p53wt tumors. J. Med. Chem. 58, 6348-6358. doi: 10.1021/acs.jmedchem. 5b00810

Hu, B., Gilkes, D. M., and Chen, J. (2007). Efficient p53 activation and apoptosis by simultaneous disruption of binding to MDM2 and MDMX. Cancer Res. 67, 8810-8817. doi: 10.1158/0008-5472.CAN-07-1140

Huang, L., Yan, Z., Liao, X., Li, Y., Yang, J., Wang, Z.-G., et al. (2011). The p53 inhibitors MDM2/MDMX complex is required for control of p53 activity in vivo. Proc. Natl. Acad. Sci. U.S.A. 108, 12001-12006. doi: 10.1073/pnas. 1102309108

Itoh, Y., Ishikawa, M., Naito, M., and Hashimoto, Y. (2010). Protein knockdown using methyl bestatin-ligand hybrid molecules: design and synthesis of inducers of ubiquitination-mediated degradation of cellular retinoic acidbinding proteins. J. Am. Chem. Soc. 132, 5820-5826. doi: 10.1021/ja100 $691 \mathrm{p}$

Itoh, Y., Kitaguchi, R., Ishikawa, M., Naito, M., and Hashimoto, Y. (2011). Design, synthesis and biological evaluation of nuclear receptor-degradation inducers. Bioorg. Med. Chem. 19, 6768-6778. doi: 10.1016/j.bmc.2011.09.041

Kamura, T., Koepp, D. M., Conrad, M. N., Skowyra, D., Moreland, R. J., Iliopoulos, O., et al. (1999). Rbx1, a component of the VHL tumor suppressor complex and SCF ubiquitin ligase. Science 284, 657-661. doi: 10.1126/science. 284.5414.657

Lai, A. C., and Crews, C. M. (2017). Induced protein degradation: an emerging drug discovery paradigm. Nat. Rev. Drug Discov. 16, 101-114. doi: 10.1038/nrd. 2016.211

Lai, A. C., Toure, M., Hellerschmied, D., Salami, J., Jaime-Figueroa, S., Ko, E., et al. (2016). Modular PROTAC design for the degradation of oncogenic BCR-ABL. Angew. Chem. Int. Ed. Engl. 55, 807-810. doi: 10.1002/anie.20150 7634

Lee, G. M., and Craik, C. S. (2009). Trapping moving targets with small molecules. Science 324, 213-215. doi: 10.1126/science.1169378

Li, Z., and Xiong, Y. (2017). Cytoplasmic E3 ubiquitin ligase CUL9 controls cell proliferation, senescence, apoptosis and genome integrity through p53. Oncogene 36, 5212-5218. doi: 10.1038/onc.2017.141

Lu, J., Qian, Y., Altieri, M., Dong, H., Wang, J., Raina, K., et al. (2015). Hijacking the E3 ubiquitin ligase cereblon to efficiently target BRD4. Chem. Biol. 22, 755-763. doi: 10.1016/j.chembiol.2015.05.009 
Lydeard, J. R., Schulman, B. A., and Harper, J. W. (2013). Building and remodelling Cullin-RING E3 ubiquitin ligases. EMBO Rep. 14, 1050-1061. doi: 10.1038/ embor.2013.173

Maniaci, C., Hughes, S. J., Testa, A., Chen, W., Lamont, D. J., Rocha, S., et al. (2017). Homo-PROTACs: bivalent small-molecule dimerizers of the VHL E3 ubiquitin ligase to induce self-degradation. Nat. Commun. 8:830. doi: 10.1038/s41467017-00954-1

Metzger, M. B., Pruneda, J. N., Klevit, R. E., and Weissman, A. M. (2014). RINGtype E3 ligases: master manipulators of E2 ubiquitin-conjugating enzymes and ubiquitination. Biochim. Biophys. Acta 1843, 47-60. doi: 10.1016/j.bbamcr.2013. 05.026

Muller, P. A. J., and Vousden, K. H. (2013). p53 mutations in cancer. Nat. Cell Biol. 15, 2-8. doi: $10.1038 / \mathrm{ncb} 2641$

Ohoka, N., Misawa, T., Kurihara, M., Demizu, Y., and Naito, M. (2017a). Development of a peptide-based inducer of protein degradation targeting NOTCH1. Bioorg. Med. Chem. Lett. 27, 4985-4988. doi: 10.1016/j.bmcl.2017. 10.011

Ohoka, N., Okuhira, K., Ito, M., Nagai, K., Shibata, N., Hattori, T., et al. (2017b). In vivo knockdown of pathogenic proteins via specific and nongenetic inhibitor of apoptosis protein (IAP)-dependent protein erasers (SNIPERs). J. Biol. Chem. 292, 4556-4570. doi: 10.1074/jbc.M116.768853

Ohoka, N., Morita, Y., Nagai, K., Shimokawa, K., Ujikawa, O., Fujimori, I., et al. (2018). Derivatization of inhibitor of apoptosis protein (IAP) ligands yields improved inducers of estrogen receptor $\alpha$ degradation. J. Biol. Chem. doi: 10. 1074/jbc.RA117.001091 [Epub ahead of print].

Ohta, T., Michel, J. J., Schottelius, A. J., and Xiong, Y. (1999). ROC1, a homolog of APC11, represents a family of cullin partners with an associated ubiquitin ligase activity. Mol. Cell 3, 535-541. doi: 10.1016/S1097-2765(00)80 $482-7$

Okuhira, K., Ohoka, N., Sai, K., Nishimaki-Mogami, T., Itoh, Y., Ishikawa, M., et al. (2011). Specific degradation of CRABP-II via cIAP1-mediated ubiquitylation induced by hybrid molecules that crosslink cIAP1 and the target protein. FEBS Lett. 585, 1147-1152. doi: 10.1016/j.febslet.2011.03.019

Pant, V., Xiong, S., Iwakuma, T., Quintás-Cardama, A., and Lozano, G. (2011). Heterodimerization of $\mathrm{Mdm} 2$ and $\mathrm{Mdm} 4$ is critical for regulating $\mathrm{p} 53$ activity during embryogenesis but dispensable for p53 and Mdm2 stability. Proc. Natl. Acad. Sci. U.S.A. 108, 11995-12000. doi: 10.1073/pnas.110224 1108

Pellegrino, M., Mancini, F., Lucà, R., Coletti, A., Giacchè, N., Manni, I., et al. (2015). Targeting the MDM2/MDM4 interaction interface as a promising approach for p53 reactivation therapy. Cancer Res. 75, 4560-4572. doi: 10.1158/0008-5472. CAN-15-0439

Petroski, M. D. (2008). The ubiquitin system, disease, and drug discovery. BMC Biochem. 9(Suppl. 1):S7. doi: 10.1186/1471-2091-9-S1-S7

Pickart, C. M. (2001). Mechanisms underlying ubiquitination. Annu. Rev. Biochem. 70, 503-533. doi: 10.1146/annurev.biochem.70.1.503

Popowicz, G. M., Czarna, A., Wolf, S., Wang, K., Wang, W., Dömling, A., et al. (2010). Structures of low molecular weight inhibitors bound to MDMX and MDM2 reveal new approaches for p53-MDMX/MDM2 antagonist drug discovery. Cell Cycle 9, 1104-1111. doi: 10.4161/cc.9.6.10956

Raina, K., Lu, J., Qian, Y., Altieri, M., Gordon, D., Rossi, A. M. K., et al. (2016). PROTAC-induced BET protein degradation as a therapy for castration-resistant prostate cancer. Proc. Natl. Acad. Sci. U.S.A. 113, 7124-7129. doi: 10.1073/pnas. 1521738113

Reed, D., Shen, Y., Shelat, A. A., Arnold, L. A., Ferreira, A. M., Zhu, F., et al. (2010). Identification and characterization of the first small molecule inhibitor of MDMX. J. Biol. Chem. 285, 10786-10796. doi: 10.1074/jbc.M109.05 6747

Sarikas, A., Hartmann, T., and Pan, Z.-Q. (2011). The cullin protein family. Genome Biol. 12:220. doi: 10.1186/gb-2011-12-4-220

Schneekloth, A. R., Pucheault, M., Tae, H. S., and Crews, C. M. (2008). Targeted intracellular protein degradation induced by a small molecule: en route to chemical proteomics. Bioorg. Med. Chem. Lett. 18, 5904-5908. doi: 10.1016/j. bmcl.2008.07.114

Seol, J. H., Feldman, R. M., Zachariae, W., Shevchenko, A., Correll, C. C., Lyapina, S., et al. (1999). Cdc53/cullin and the essential Hrt1 RING-H2 subunit of SCF define a ubiquitin ligase module that activates the E2 enzyme Cdc34. Genes Dev. 13, 1614-1626. doi: 10.1101/gad.13.12.1614
Shibata, N., Miyamoto, N., Nagai, K., Shimokawa, K., Sameshima, T., Ohoka, N., et al. (2017). Development of protein degradation inducers of oncogenic BCRABL protein by conjugation of ABL kinase inhibitors and IAP ligands. Cancer Sci. 108, 1657-1666. doi: 10.1111/cas.13284

Shibata, N., Nagai, K., Morita, Y., Ujikawa, O., Ohoka, N., Hattori, T., et al. (2018). Development of protein degradation inducers of androgen receptor by conjugation of androgen receptor ligands and inhibitor of apoptosis protein ligands. J. Med. Chem. 61, 543-575. doi: 10.1021/acs.jmedchem.7b 00168

Soares, P., Gadd, M. S., Frost, J., Galdeano, C., Ellis, L., Epemolu, O., et al. (2018). Group-based optimization of potent and cell-active inhibitors of the von Hippel-Lindau (VHL) E3 ubiquitin ligase: structure-activity relationships leading to the chemical probe (2S,4R)-1-((S)-2-(1-cyanocyclopropanecarboxamido)-3,3-dimethylbutanoyl)4-hydroxy-N-(4-(4-methylthiazol-5-yl)benzyl)pyrrolidine-2-carboxamide (VH298). J. Med. Chem. 61, 599-618. doi: 10.1021/acs.jmedchem.7b0 0675

Soucy, T. A., Smith, P. G., Milhollen, M. A., Berger, A. J., Gavin, J. M., Adhikari, S., et al. (2009). An inhibitor of NEDD8-activating enzyme as a new approach to treat cancer. Nature 458, 732-736. doi: 10.1038/nature07884

Spratt, D. E., Walden, H., and Shaw, G. S. (2014). RBR E3 ubiquitin ligases: new structures, new insights, new questions. Biochem. J. 458, 421-437. doi: 10.1042/ BJ20140006

Sun, Y. (2005). Overview of approaches for screening for ubiquitin ligase inhibitors. Methods Enzymol. 399, 654-663. doi: 10.1016/S0076-6879(05)9 9043-5

Swords, R. T., Erba, H. P., DeAngelo, D. J., Bixby, D. L., Altman, J. K., Maris, M., et al. (2015). Pevonedistat (MLN4924), a First-in-Class NEDD8-activating enzyme inhibitor, in patients with acute myeloid leukaemia and myelodysplastic syndromes: a phase 1 study. Br. J. Haematol. 169, 534-543. doi: 10.1111/bjh. 13323

Tan, P., Fuchs, S. Y., Chen, A., Wu, K., Gomez, C., Ronai, Z., et al. (1999). Recruitment of a ROC1-CUL1 ubiquitin ligase by Skp1 and HOS to catalyze the ubiquitination of I к B $\alpha$. Mol. Cell 3, 527-533. doi: 10.1016/S1097-2765(00) 80481-5

Thiel, P., Kaiser, M., and Ottmann, C. (2012). Small-molecule stabilization of protein-protein interactions: an underestimated concept in drug discovery? Angew. Chem. Int. Ed. Engl. 51, 2012-2018. doi: 10.1002/anie.20110 7616

Tisato, V., Voltan, R., Gonelli, A., Secchiero, P., and Zauli, G. (2017). MDM2/X inhibitors under clinical evaluation: perspectives for the management of hematological malignancies and pediatric cancer. J. Hematol. Oncol. 10:133. doi: 10.1186/s13045-017-0500-5

Van Molle, I., Thomann, A., Buckley, D. L., So, E. C., Lang, S., Crews, C. M., et al. (2012). Dissecting fragment-based lead discovery at the von Hippel-Lindau protein:hypoxia inducible factor $1 \alpha$ protein-protein interface. Chem. Biol. 19, 1300-1312. doi: 10.1016/j.chembiol.2012.08.015

Vassilev, L. T., Vu, B. T., Graves, B., Carvajal, D., Podlaski, F., Filipovic, Z., et al. (2004). In vivo activation of the $\mathrm{p} 53$ pathway by small-molecule antagonists of MDM2. Science 303, 844-848. doi: 10.1126/science.1092472

Vu, B., Wovkulich, P., Pizzolato, G., Lovey, A., Ding, Q., Jiang, N., et al. (2013). Discovery of RG7112: a small-molecule MDM2 inhibitor in clinical development. ACS Med. Chem. Lett. 4, 466-469. doi: 10.1021/ml400 0657

Winter, G. E., Buckley, D. L., Paulk, J., Roberts, J. M., Souza, A., Dhe-Paganon, S., et al. (2015). DRUG DEVELOPMENT. Phthalimide conjugation as a strategy for in vivo target protein degradation. Science 348, 1376-1381. doi: 10.1126/ science.aab1433

Xirodimas, D. P., Saville, M. K., Bourdon, J.-C., Hay, R. T., and Lane, D. P. (2004). Mdm2-mediated NEDD8 conjugation of p53 inhibits its transcriptional activity. Cell 118, 83-97. doi: 10.1016/j.cell.2004.06.016

Zaytsev, A., Dodd, B., Magnani, M., Ghiron, C., Golding, B. T., Griffin, R. J., et al. (2015). Searching for dual inhibitors of the MDM2-p53 and MDMX-p53 protein-protein interaction by a scaffold-hopping approach. Chem. Biol. Drug Des. 86, 180-189. doi: 10.1111/cbdd.12474

Zengerle, M., Chan, K.-H., and Ciulli, A. (2015). Selective small molecule induced degradation of the BET bromodomain protein BRD4. ACS Chem. Biol. 10, 1770-1777. doi: 10.1021/acschembio.5b00216 
Zhang, B., Golding, B. T., and Hardcastle, I. R. (2015). Small-molecule MDM2-p53 inhibitors: recent advances. Future Med. Chem. 7, 631-645. doi: 10.4155/fmc. 15.13

Zhao, Y., Liu, L., Sun, W., Lu, J., McEachern, D., Li, X., et al. (2013). Diastereomeric spirooxindoles as highly potent and efficacious MDM2 inhibitors. J. Am. Chem. Soc. 135, 7223-7234. doi: 10.1021/ja3125417

Zhao, Y., and Sun, Y. (2013). Cullin-RING Ligases as attractive anti-cancer targets. Curr. Pharm. Des. 19, 3215-3225. doi: 10.2174/13816128113199990300

Zheng, N., Schulman, B. A., Song, L., Miller, J. J., Jeffrey, P. D., Wang, P., et al. (2002). Structure of the Cul1-Rbx1-Skp1-F boxSkp2 SCF ubiquitin ligase complex. Nature 416, 703-709. doi: 10.1038/416703a

Zhou, B., Hu, J., Xu, F., Chen, Z., Bai, L., Fernandez-Salas, E., et al. (2017). Discovery of a small-molecule degrader of bromodomain and extra-terminal (BET) proteins with picomolar cellular potencies and capable of achieving tumor regression. J. Med. Chem. 61, 462-481. doi: 10.1021/acs.jmedchem. $6 \mathrm{~b} 01816$

Conflict of Interest Statement: The authors declare that the research was conducted in the absence of any commercial or financial relationships that could be construed as a potential conflict of interest.

Copyright (C) 2018 Bulatov, Zagidullin, Valiullina, Sayarova and Rizvanov. This is an open-access article distributed under the terms of the Creative Commons Attribution License (CC BY). The use, distribution or reproduction in other forums is permitted, provided the original author(s) and the copyright owner are credited and that the original publication in this journal is cited, in accordance with accepted academic practice. No use, distribution or reproduction is permitted which does not comply with these terms. 